\title{
Equatorial aerosol-ozone structure and variations as observed by balloon-borne backscattersondes since 1995 at Natal, Brazil $\left(6^{\circ} \mathrm{S}\right)$
}

\author{
James M. Rosen, Raymond M. Morales, and Norman T. Kjome \\ Department of Physics and Astronomy, University of Wyoming, Laramie, Wyoming, USA \\ Volker W. J. H. Kirchhoff \\ Laboratorio Ozonio, Instituto Nacional de Pequisas Espaciais (INPE), São José dos Campos, Brazil
}

Francisco R. da Silva

Laboratorio Ozonio, Instituto Nacional de Pequisas Espaciais (INPE), Natal, Brazil

Received 24 April 2003; revised 5 August 2003; accepted 12 November 2003; published 3 February 2004.

[1] Simultaneous aerosol and ozone profiles have been measured near Natal, Brazil $\left(6.07^{\circ} \mathrm{S}, 35.34^{\circ} \mathrm{W}\right)$ in an irregular but continuing effort since 1995 using balloon-borne backscattersondes. This study introduces the primary features of the data set and our preliminary interpretation. Although measurements from ground level to $\sim 32 \mathrm{~km}$ are made, the results reported here focus on the free troposphere (FT). An apparent clear annual cycle in the occurrence of FT aerosol layers is observed, which peaks during the biomass burning season, similar to the previously reported annual cycle in tropical ozone layers. A majority of the layers occurring during the burning season contain enhancements of both aerosol and ozone. The comparatively low amounts of aerosol backscatter enhancements found in the FT layers indicate that any aerosols originating in the much higher concentrations of the planetary boundary layer (PBL) must have been greatly reduced in backscatter before they were observed in the soundings. In general, the FT backscatter profile over Natal can be described as displaying a background or baseline character that is frequently perturbed by layers of various concentrations and thicknesses. Although only the last stages of the Pinatubo volcanic aerosol decay were observed, a curious multiple-step reduction in the aerosol was seen in the profiles near $20 \mathrm{~km}$. Because the soundings were conducted with varying regularity in a limited time period, current interpretation of results can only be considered tentative. INDEX TERMS: 0305 Atmospheric Composition and Structure: Aerosols and particles (0345, 4801); 0345 Atmospheric Composition and Structure: Pollution — urban and regional (0305); 0368 Atmospheric Composition and Structure:

Troposphere - constituent transport and chemistry; KEYWORDS: aerosol, ozone, backscattering

Citation: Rosen, J. M., R. M. Morales, N. T. Kjome, V. W. J. H. Kirchhoff, and F. R. da Silva (2004), Equatorial aerosol-ozone structure and variations as observed by balloon-borne backscattersondes since 1995 at Natal, Brazil (6 ${ }^{\circ}$ S), J. Geophys. Res., 109, D03201, doi:10.1029/2003JD003715.

\section{Introduction}

[2] Aerosols have long been recognized as an important component in a wide range of atmospheric processes. The possible role of volcanic aerosols in shaping long term climate variations has been the subject of many studies. More recently considerable attention has been given to quantitatively identifying the radiative impact of tropospheric aerosols in relation to the overall assessment of global warming. Aerosols are also an essential component of atmospheric chemistry because they may provide sites for surface reactions and form from trace gas species whose reaction products have sufficiently low effective vapor pressures for condensation. Since aerosols are easily and routinely measured at the sub ppbm level, they can provide

Copyright 2004 by the American Geophysical Union. 0148-0227/04/2003JD003715 a very sensitive method of identifying perturbations from normal conditions, chemically active air masses, sources and sinks, and atmospheric transport.

[3] The present study, which began on an irregular basis in 1995, employs the backscattersonde for a high-resolution quantitative measurement of aerosols in an altitude and latitude region that was notably lacking in systematic observations, namely, the equatorial free troposphere extending from the PBL top to the tropopause. We also obtain measurements throughout the PBL and stratosphere, and while such information is frequently useful for interpreting aspects of the FT aerosol, they are not the principal focus of the present report. To assist in the interpretation of the aerosol profiles and to provide further insights, simultaneous measurements of ozone, temperature, relative humidity ( $\mathrm{RH})$, and pressure are also part of the standard backscattersonde data system. 
[4] In this report we present an overview of initial results, which are based on 31 soundings. Two of these soundings were made at Cuiabá, Brazil $\left(16^{\circ} \mathrm{S}, 56^{\circ} \mathrm{W}\right)$ in September and October 1995 (peak of the biomass burning season at that location) and the remainder were made at Natal, Brazil $\left(5.8^{\circ} \mathrm{S}, 35.2^{\circ} \mathrm{W}\right)$ from November 1995 to December 2002. In particular, we begin here by addressing the following questions and issues concerning the tropical FT: (1) Is there an annual cycle in the aerosol profiles similar to known cycles in ozone and biomass burning? (2) Is there an identifiable FT background or baseline profile similar to that found at other latitudes? (3) What are the probable source regions of the perturbing layers as inferred through back trajectory analysis? (4) To what extent do the burning season aerosol perturbations enhance the column loadings of the FT?

[5] Our current equatorial backscattersonde program is a continuing effort with monthly soundings, and it is expected that future papers will appear describing results not treated here as well as updating and elaborating previous findings. The full data set will be made available through the Network for Detection of Stratospheric Change (NDSC) web site data base (www.ndsc.ncep.noaa.gov), which at present contains most of the backscattersonde data from other latitudes.

\section{Instrumentation}

[6] The backscattersonde was first described by Rosen and Kjome [1991] and has since been frequently employed in studies similar to the work here but for northern and southern midlatitudes [Rosen et al., 1997, 2000; Liley et al., 2001], for arctic regions [Suortti et al., 2001], and for Antarctica [Rosen et al., 1993]. A further description of the accuracy, errors, resolution, calibration, calibration stability, and supporting onboard integrated sensors (pressure, temperature, $\mathrm{RH}$ and ozone) has been given by Rosen et al. [2000].

[7] Briefly, the balloon-borne instrument measures the local ambient backscattered light at two wavelengths of nominally $940 \mathrm{~nm}$ (red channel) and $490 \mathrm{~nm}$ (blue channel) wavelength and thus is not a remote sensing type device. The resulting aerosol data product is similar to profiles obtained with high-resolution, low-noise lidar but has the decided advantage of concurrent air temperature, ozone and $\mathrm{RH}$, as well as pressure information. In addition, profiles can be obtained in cloudy conditions. It should also be noted that the aerosols are observed truly in situ and are not subject to modification by inlet sampling, sedimentation and/or evaporation as might occur in other types of sampling techniques.

[8] Before flight every instrument is absolutely calibrated in the sense that the signal for aerosol free air under ambient temperature and pressure conditions is known. Thus the backscatter ratio (BKSR, ratio of signal to aerosol free signal) and the aerosol backscatter ratio (ABKSR = BKSR-1) can be calculated throughout each flight using the preflight calibration as well as the ambient pressure and temperature to adjust the surface level calibration to ambient conditions. This procedure does not require any normalization to presumed aerosol free air occurring somewhere in the profile, as is assumed in many lidar data reduction schemes. The short term stability of the calibrated instruments can be determined by the repeatability of the stratospheric profiles in ascent-descent profiles and the longer

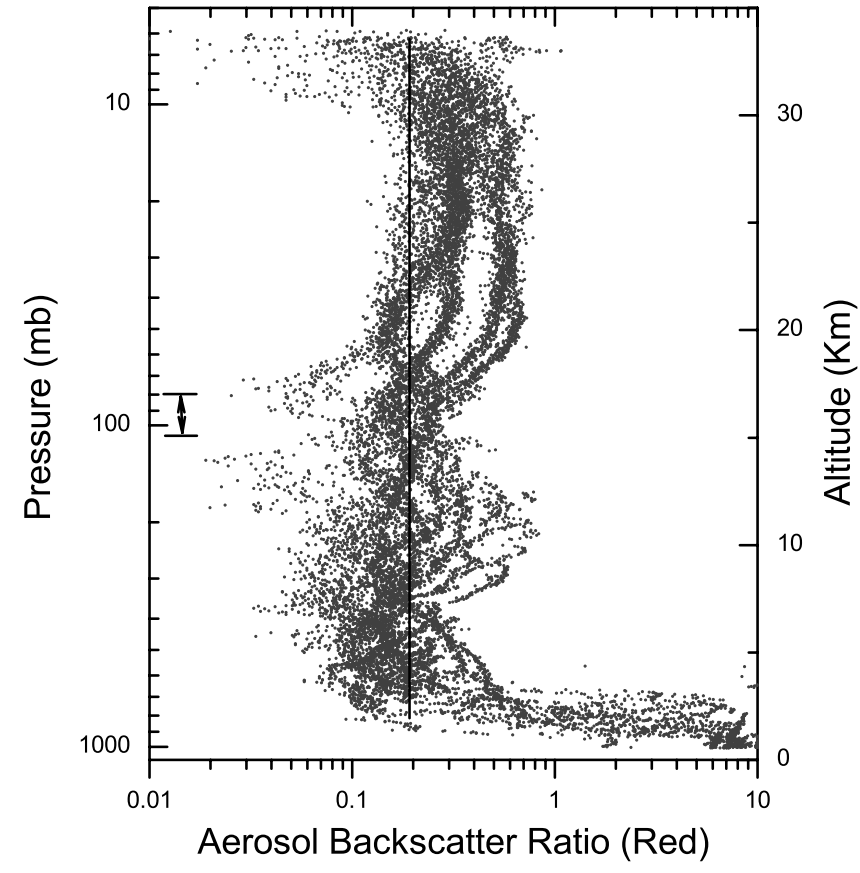

Figure 1. Composite of all soundings made in Brazil from August 1995 to December 1998. The range of observed tropopause heights are indicated by the bar near $15 \mathrm{~km}$ in Figures 1 and 3-6. The right-hand altitude scale in Figures 1 and 3-6 is approximate with an error of about $0.1 \mathrm{~km}$. The close point clusters in the PBL with sloping pattern upward to the right indicate signal saturation in Figures 1 and 3-6.

term calibration stability can be assessed by comparing profiles over periods of stable stratospheric conditions, as found in the soundings since 1995 and exemplified by the lowest stratospheric values shown in Figure 1.

[9] The two wavelength measurements allow for a crude size estimate of the aerosol particles. In practice only three size ranges are clearly identifiable, namely "small", "medium" and "large." Experience shows that the large particles include clouds and wind blown dust, while most other natural aerosols fall into the medium size range. Very large numbers of fine particles (such as condensation nuclei) are needed to obtain a sufficient signal to identify particles in the small range. A color index $(\mathrm{CI}=\mathrm{ABKSR} \mathrm{red} / \mathrm{ABKSR}$ blue) has been defined to help quantitatively categorize the sizes. Usually aerosol CI falls between $\sim 4$ and $\sim 6$, while wind blown dust is $\sim 10$, and cloud particles are above 10 and usually closer to 15 . A more quantitative effort to relate CI to particle size for various size distributions is given by Rosen and Kjome [1991] and supports the quantitative CI values given above.

[10] The pressure, temperature, and $\mathrm{RH}$ measurements are made with the well known Vaisala RS80 sensors which undergo a pressure recalibration check in our laboratory before every flight. Although the accuracy of the pressure and temperature sensors are more than sufficient for the backscattersonde analysis, it is known that the RH sensor requires a temperature correction, especially for the middle and upper troposphere [Carlson and Wang, 2002] and does not produce a useful response in the very dry air of the 
stratosphere. We have developed our own temperature correction algorithm based on the average response of the Vaisala sensors used in our soundings in conjunction with the requirement that the frost point equals the air temperature in upper tropospheric clouds (as detected by the backscattersonde). This can only be considered an approximate general correction, since each sensor may differ somewhat in the required correction factor and the frost point in clouds is not necessarily equal to the local air temperature [Ovarlez et al., 2002]. However, when plotting our algorithmic frost point with the temperature profile as an analysis tool, the frost point visually appears essentially equal to the air temperature in clouds in almost all cases, as would be expected for a perfect correction. Thus we believe that our frost point algorithm used in this way with the temperature profile plots provides a useful supporting tool to aid in the general identification of saturated or nearly saturated air where the probability of cloud occurrence is expected to be high. It might also be noted that comparison of ascent and descent frost point profiles usually shows good agreement to temperatures as low as $-65^{\circ} \mathrm{C}$ which addresses the question of sensor response and repeatability. However, the reader is warned that while our frost point algorithm may be justified as a specifically focused analysis tool, it would not necessarily yield water vapor mixing ratio values of sufficient accuracy to address most questions of interest, since the uncertainty in frost point will lead to a large error in mixing ratio.

[11] The ozone sensor is an electro-chemical cell (ECC) type and prepared in the same manner and by the same personnel that launch ozonesondes from Natal as part of the SHADOZ network [Thompson et al., 2003].

\section{Atmospheric Setting and Conditions}

[12] The balloon launches take place from Monte Alegre $\left(6.07^{\circ} \mathrm{S}, 35.34^{\circ} \mathrm{W}\right)$, a small town about $35 \mathrm{~km}$ southwest of Natal and about $25 \mathrm{~km}$ inland. The typical time of release is $\sim 2$ hours after local sunset and not during extended rainy conditions or local rain showers.

[13] A very pronounced PBL is almost always present, being easily identified at the top $(3.0 \pm 0.6 \mathrm{~km})$ by a temperature inversion, sudden large drop in ABKSR as well as RH. Although the ABKSR is relatively large in the PBL at Monte Alegre, it does not appear to be significantly different from observed coastal surface conditions, which are heavily influenced by the flushing action of the trade winds. Visually the air in the region usually appears relatively clear, suggesting that the area is not heavily influenced by local pollution probably because most potential sources are downwind. During fire season, Natal is outside the main burning regions as is evident from satellite observations [Kaufman et al., 1998; Prins et al., 1998].

[14] The location of the tropopause in our soundings $\left(16.7 \pm 0.6 \mathrm{~km},-80.7 \pm 2{ }^{\circ} \mathrm{C}\right)$ is usually unambiguously identified in the temperature structure with a large, consistent change in lapse rate occurring at or close to the minimum temperature and near a location where ozone abruptly starts a monotonic increase to stratospheric values. For our soundings these parameter changes take place within about a $1 \mathrm{~km}$ thick region (or less) so that there is a relatively small uncertainty in the tropopause locations indicated in the relevant figures below.
[15] Winds aloft might be described as light and variable from the experience of only a few soundings. The balloon usually ascends approximately strait overhead and lands a few tens of $\mathrm{km}$ from the launch site. Although the average winds aloft could be described systematically in terms of periodic variations using larger databases, it has proven to be more applicable for our current limited soundings to simply use back trajectory calculations related to the sounding of interest.

\section{Results}

\subsection{Preliminary: Cloud Removal}

[16] In the data presented here except in one noted example, cloud layers have been removed for improved clarity. There is little ambiguity in identifying cloud layers since abrupt and continuing significant changes in the ABKSR are observed when the backscattersonde enters or exits a cloud. In addition, the CI reflects a major change when entering a cloud, indicating much larger particles. Our frost point algorithm also provides independent supporting evidence that will suggest if cloud conditions are probable, not probable, or not possible, depending on the frost point depression and measurement uncertainty. The profiles shown here would not appear drastically different if the cloud data were included because that data would be off scale (or nearly off scale) and only a few of the cloud edge points would show in the noncloud regions. Since the data set is fairly small, we prefer to inspect each sounding separately to make sure no probable cloud or cloud edge data is included. As more data accumulates, it should be possible to develop a more objective computer based algorithm for reliably removing cloud and cloud edge data. However, at present we do not consider this to be a significant issue.

\subsection{Overview of 1995-1999: Volcanic Decay Phase}

[17] It is convenient to first present an overview of the first 18 soundings made in Brazil covering the years 1995 to 1999 since this embraces the final stages of the Mt. Pinatubo volcanic decay period which impacts the interpretation of FT aerosols in the tropopause region. Figure 1 is a composite of these soundings (including the two Cuiabá profiles) in which the full resolution data has been plotted as single points and without any smoothing or averaging (but with clouds removed). The higher ABKSR associated with the PBL and the variability of aerosols in the 7 to $15 \mathrm{~km}$ region are easily recognized. Near the $20 \mathrm{~km}$ level the 18 profiles appear to be gathered into 4 distinct groups with the ABKSR decreasing in steps monotonically in time.

[18] To address possible reasons for the $20 \mathrm{~km}$ profile grouping, a more detailed illustration of the time development is given in Figure 2 along with other possibly relevant phenomena such as the quasi-biennial oscillation (QBO) phase at 50-70 mb over Singapore [Huesmann and Hitchman, 2001]. As can be seen, the QBO changes are not well correlated with our observed changes in aerosols. Also shown in Figure 2 are changes in vertical transport at $20 \mathrm{~km}$ from down to up as denoted by the arrows along the bottom which were deduced from satellite observations of equatorial trace gas variations by Niwano and Shiotani [2001]. For clarity, changes in transport from up to down are not shown since they do not appear to be correlated with 


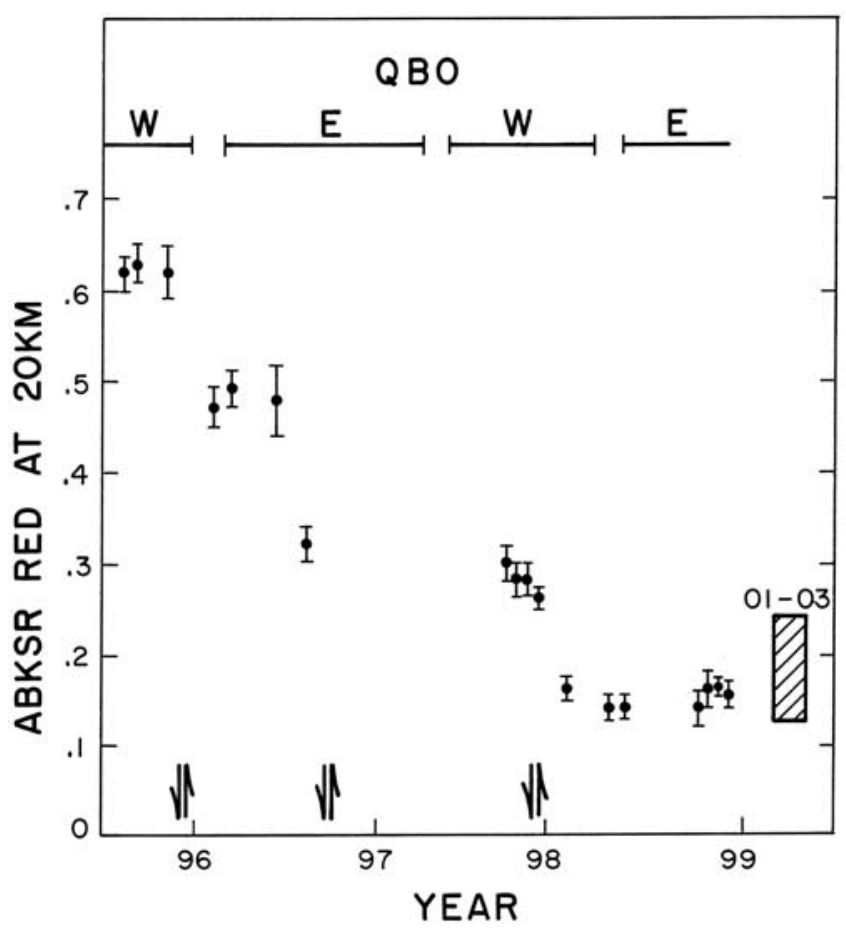

Figure 2. The red channel ABKSR at $20 \mathrm{~km}$ for the flights shown in Figure 1. The east and west phase of the QBO near $20 \mathrm{~km}$ is indicated and the down/up arrows along the bottom mark the transition from net down to net up transport at $20 \mathrm{~km}$ in the tropics as described and referenced in the text. The box on the lower right indicates the range of values observed since 1999 .

the aerosol changes. It would appear that there is an approximate simultaneity between the observed abrupt aerosol changes and the arrows along the bottom (signaling change in vertical transport). However, because the data is lacking in good time resolution including one rather large interval of no observations, the possibility must be considered that the apparent step decay may be fortuitous and would not be supported if more data were available. For example, if a short term aerosol increase occurred in late 1996 to late 1997, a period of no observations, the interpretation of Figure 2 might be considerably different. Thus it is not possible using the backscattersonde data alone to come to a definitive conclusion concerning the reason for the step decay at $20 \mathrm{~km}$ as observed in our data. On the other hand, in viewing Figure 1, it would seem more than just chance that 18 soundings would be arranged into 4 such distinct successive profile groups near $20 \mathrm{~km}$.

\subsection{PBL Aerosols}

[19] Although the PBL is not of primary concern here, it is necessary to have some knowledge of the typical near surface ABKSR since the PBL may be a significant potential supplier of aerosols to the FT through deep convective activity and other processes. As shown in Figure 1 and the other profiles illustrated below, the ABKSR in the PBL at Natal is typically 40 times more than the baseline FT aerosols. In Brazilian regions under the influence of local biomass burning, such as Cuiabá, the PBL ABKSR is considerably more than at Natal [Rosen and Kirchhoff, 1997]. Thus the aerosols of the PBL have a very large perturbing potential on the relatively clean FT, especially in burning regions.

\subsection{Free Troposphere Aerosols}

[20] To elucidate a possible seasonal variation that may be obscured in Figure 1, the soundings have been arranged into two groups: those occurring during months generally associated with biomass burning ( $\sim$ August through $\sim$ November) and the other months.

[21] Inspection of the nonburning season soundings at Natal as shown in Figures 3 and 4 would appear to support the existence of two profile types: one associated with the marine free troposphere (MFT, Figure 3) and another associated with the continental free troposphere (CFT, Figure 4). These profile types have been observed and described for other latitudes [Rosen et al., 1997]. The MFT profile is characterized by a rapid drop in ABKSR to minimal levels at the top of the PBL (as might result from lack of local sources and minimal transport across the PBL top combined with effective removal mechanisms above the PBL) while the CFT profile displays a region of noticeable slower or gradual decreasing ABKSR above the PBL (as might be consistent with stronger upward mixing of local aerosols from the surface but with decreasing effective efficiency as altitude increases). However, when compared to other latitudes, the CFT profiles at Natal show an additional sudden modest drop at the top of the PBL. This may suggest a more effective inversion capping at the equatorial PBL top and/or the influence of the MFT profiles.

[22] The profiles in Figures 3 and 4 were selected for illustration because they are relatively free of large variations or layering activity in the FT. There are two additional soundings (not shown) for this nonburning season group, which display some modest enhancements and layering activity not entirely consistent with the quiet conditions represented by Figures 3 and 4. One of the soundings falls

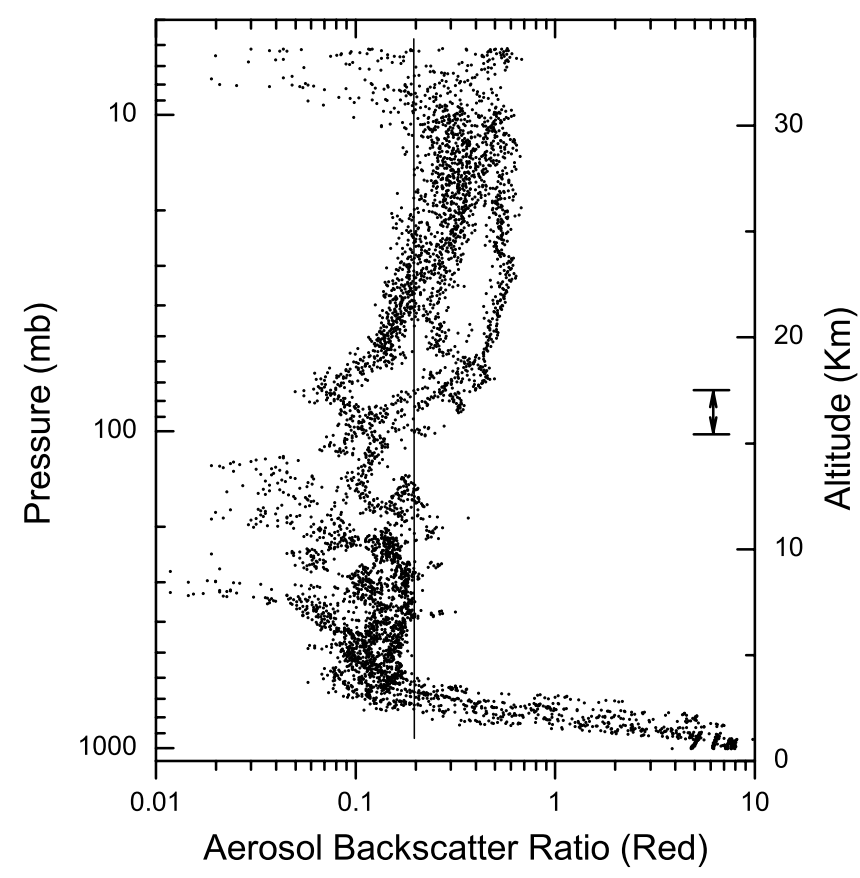

Figure 3. Composite of nondisturbed MFT type soundings for nonburning season. 


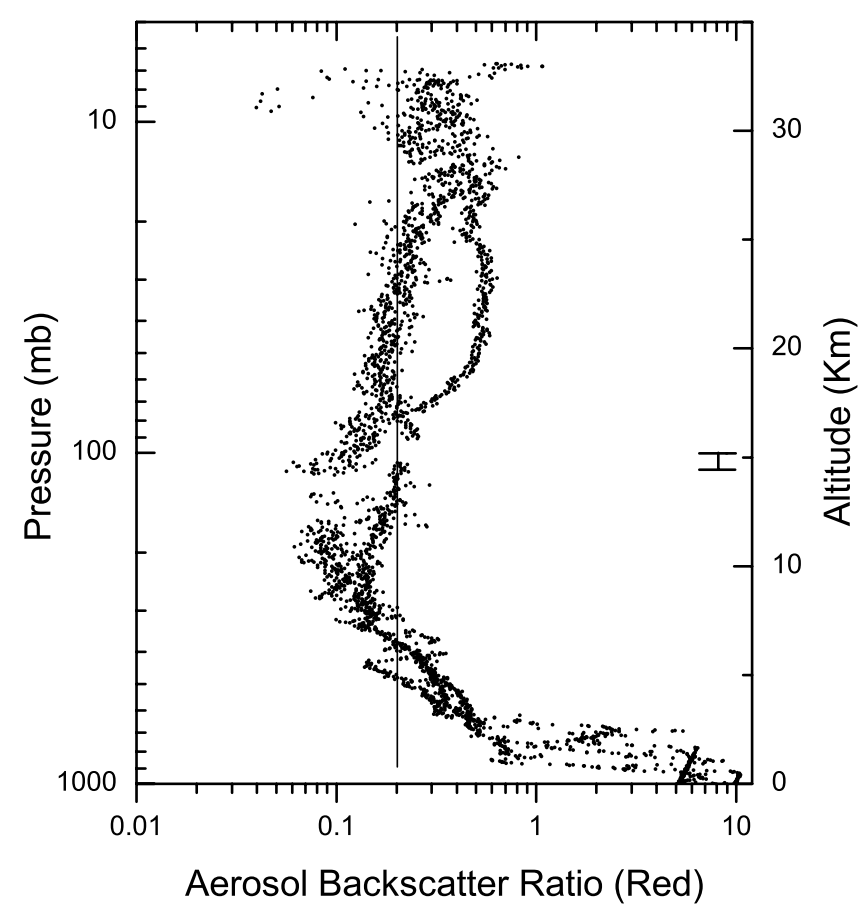

Figure 4. Composite of nondisturbed CFT type soundings for nonburning season.

into the CFT type profile and the other belongs to the MFT type profile. Thus Figures 3 and 4 probably represent the undisturbed background or baseline conditions for the FT over Natal.

[23] Figure 5 illustrates all of the Natal biomass burning month profiles (16) along with the simultaneously measured ozone. In contrast to Figures 3 and 4, Figure 5 profiles show a considerable amount of layering or perturbations in the FT, presumably associated with biomass burning. In addition, the associated ozone mixing ratio profiles are clearly systematically above the 1978-1997 mean profile (thick solid line) as determined from all available ozonesondes at Natal. The high-FT ozone levels observed at Natal and other equatorial sites are thought to be associated with biomass burning and perhaps circulation patterns [Kirchhoff et al., 1991; Oltmans et al., 2001; Thompson et al., 2003].

[24] Figure 6 is a composite of profiles observed during and slightly after only one burning season (August through December 2002 in this case), well after the stratosphere has reached stable background aerosol levels following the Pinatubo eruption. Figure 6 illustrates the same general characteristics as Figure 5 but with the clearer appearance of perturbing layers up to $20 \mathrm{~km}$ altitude, which were obscured by the volcanically enhanced stratospheric profiles included in Figure 5. A detailed individual examination of these profiles indicates that the most of these highest altitude layers definitely occur above the local tropopause. A further discussion of these transtropopause layers and their possible explanation is given below.

[25] Figures 7, 8, and 9 illustrate individual ABKSR and ozone profiles with distinctive layers occurring during the biomass burning season. In each of these examples a layer of enhanced ozone occurs with an aerosol layer. Also it is clear that not all layers present contain both aerosol and ozone enhancements.

\section{Discussion}

\subsection{Aerosol and Ozone Correlations}

[26] Figure 10 is an attempt to be more quantitative concerning our limited information relating to the aerosol/ ozone structures. In the Natal soundings 30 distinct layers of

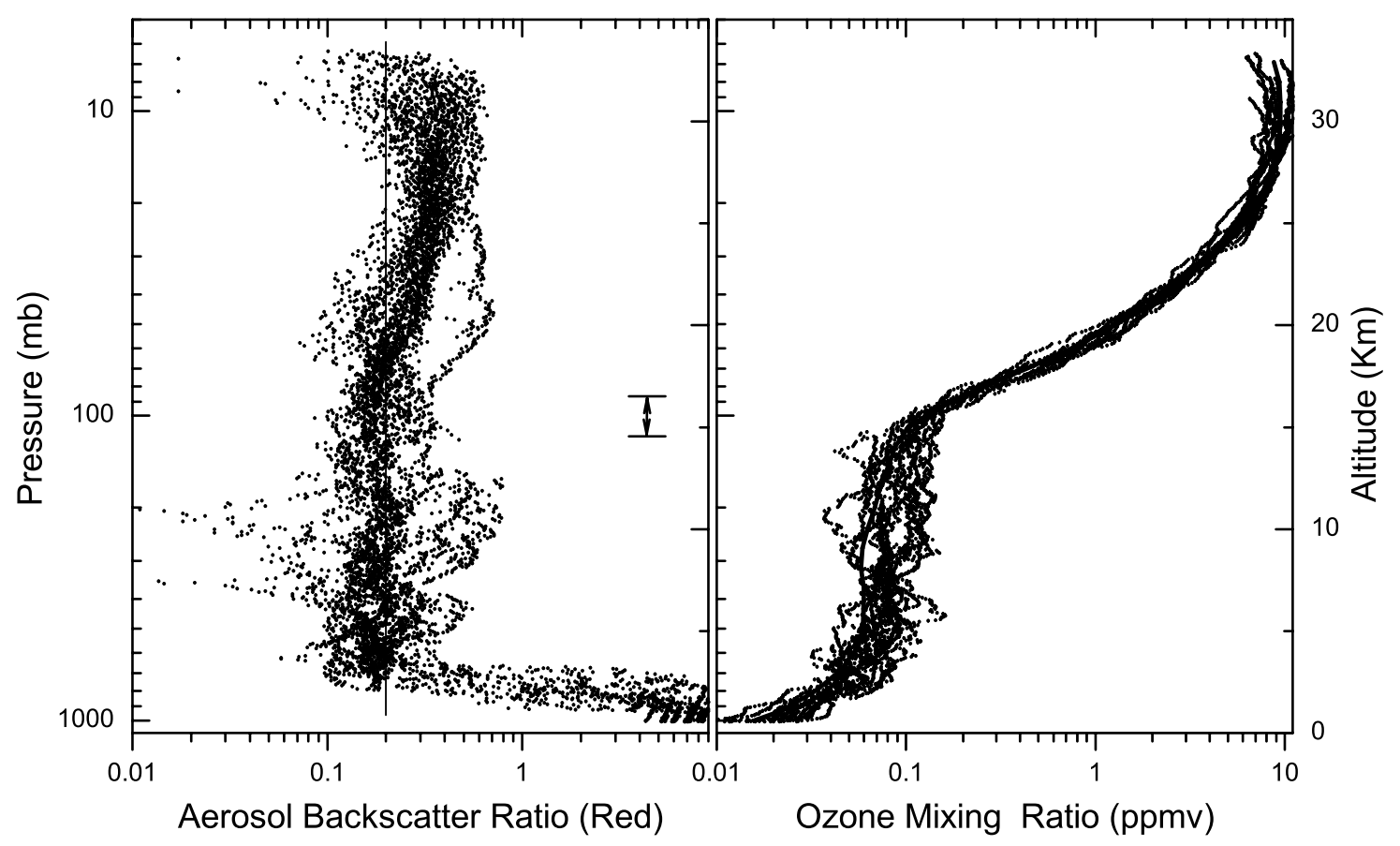

Figure 5. Composite of all aerosol and ozone profiles occurring during the burning season (AugustNovember). The solid ozone curve is the average of all 1978-1997 ozone soundings at Natal. 


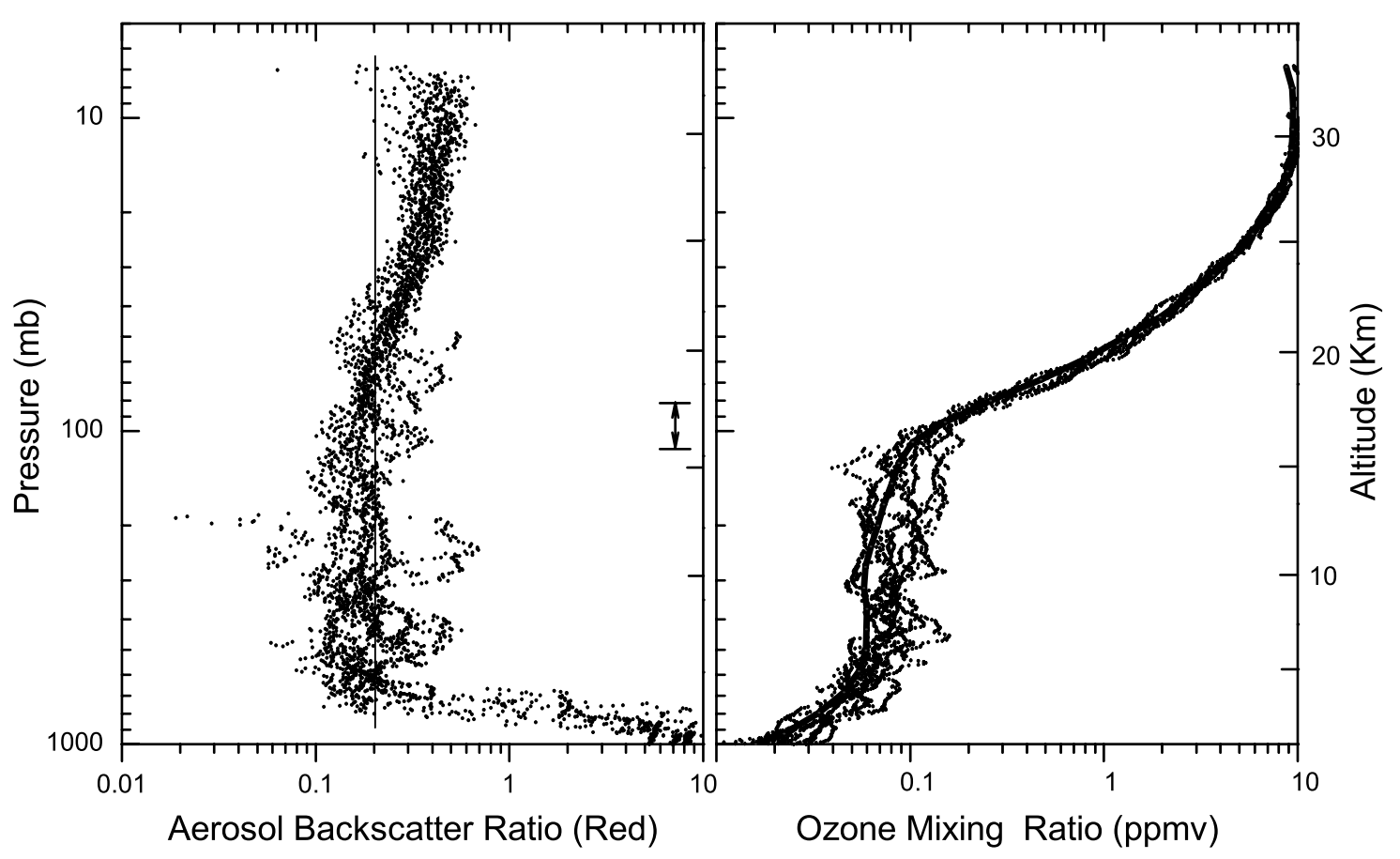

Figure 6. Same as Figure 5 except for August through December 2002.

aerosol and/or ozone were identified and roughly quantified according to their content in excess of the average or baseline conditions as determined from the average of the typical values just below and above the layer. It should be noted that any layer appearing in Figure 10 that contains both aerosol and ozone has well correlated profile structures and in this sense these layers all have high aerosol/ozone correlation even though there are varying relative concentrations. The results show that of all aerosol/ozone correlated layers, $88 \%$ occur in the biomass burning season August through November. During the burning season $63 \%$ of the layers contain enhancements of both ozone and aerosol as apposed to $28 \%$ during the nonburning season. It may also be noted from Figure 10 that there are 14 cases for which the aerosol and ozone layers do not appear concurrently. Apparently several types of layers are present and their full explanation may require elaborate scenarios, an effort beyond the scope of this report.

[27] It should be noted that the $14 \mathrm{~km}$ ozone layer in Figure 9 taken by itself might be interpreted as simply originating in the stratosphere since it contains ozone concentrations typical of the lower stratosphere and it is in close proximity to a stratospheric ozone source. However, the ABKSR of the layer is in considerable excess of the stratospheric values, suggesting that the layer is not of direct stratospheric origin. Also, 10 day back trajectory analysis of this layer indicates it was in the FT for the duration. Thus auxiliary information can provide essential information for interpreting ozone profiles.

\subsection{Layer Trajectories}

[28] Ten day back trajectories have been calculated for the layers of Figure 10 using the NOAA ARL website (www.arl. noaa.gov/ready; see Draxler [1996] for a description of the methods based on a kinematics approach). A summary of the general findings is shown in Figure 11, which indicates the layer altitude at Natal and possible source regions. Since the trajectories are often quite circuitous, there may be more than one potential source region. For example, several layers in the first two groups have also passed near the ITCZ and so

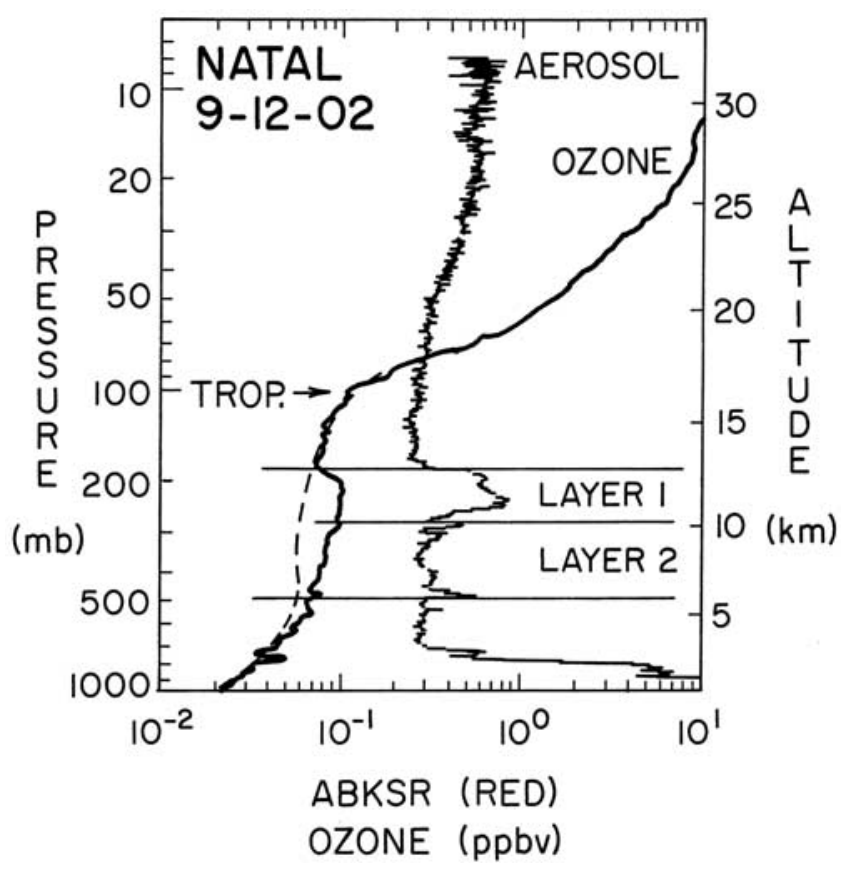

Figure 7. Example of an aerosol/ozone layer correlation observed during the burning season. As determined from 10 day back trajectory calculations, layer 1 is most likely from Brazil and South America, while layer 2 is likely from the Atlantic or Africa. The dashed line in Figures $7-9$ is the average of all 1978-1997 ozone soundings at Natal. 


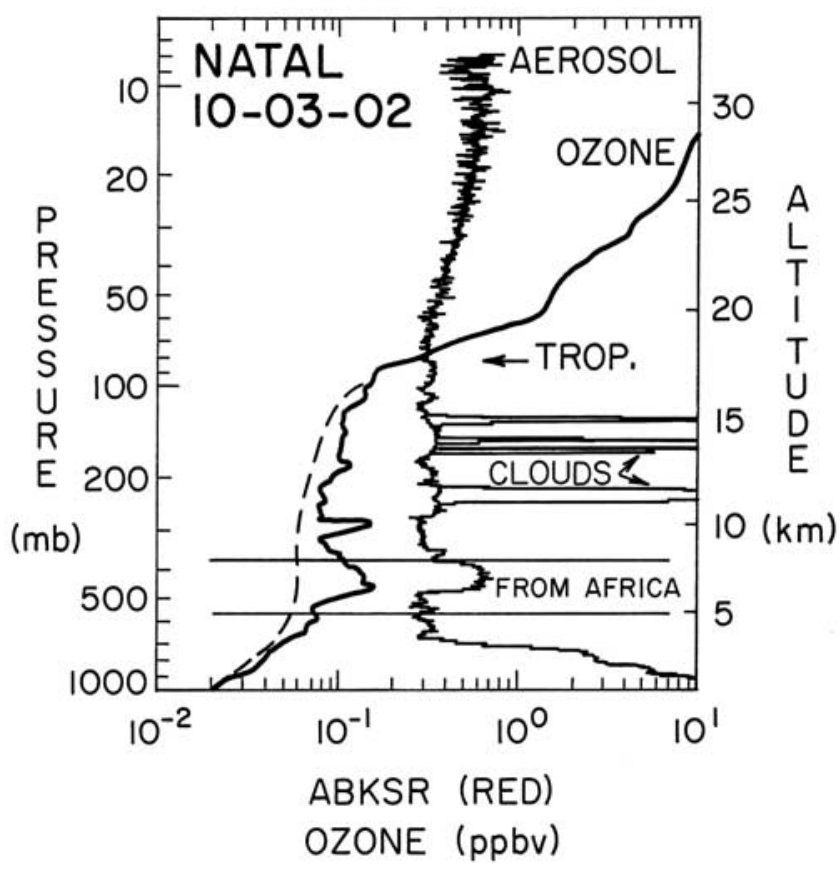

Figure 8. Example of an aerosol/ozone layer observed during the burning season. Note that the cloud layers have not been removed in this example. On descent the clouds had apparently evaporated, and the illustrated profile reflects the descent values where the clouds were present on ascent. Back trajectory analysis indicates that the identified layer was slowly descending (consistent with the low RH observed, not shown) and came to Natal from the Atlantic or Africa.

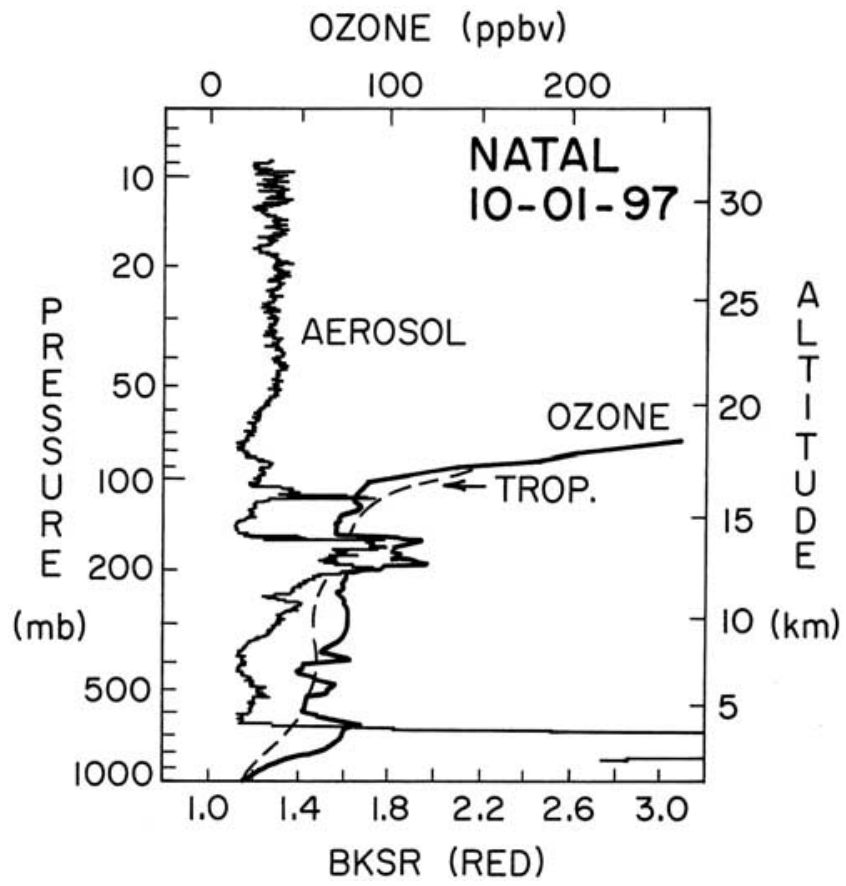

Figure 9. Example of aerosol/ozone layer correlation observed during the burning season. For this layer (near $200 \mathrm{mb}$ ) the back trajectory suggests a source from central Brazil or the ITCZ.

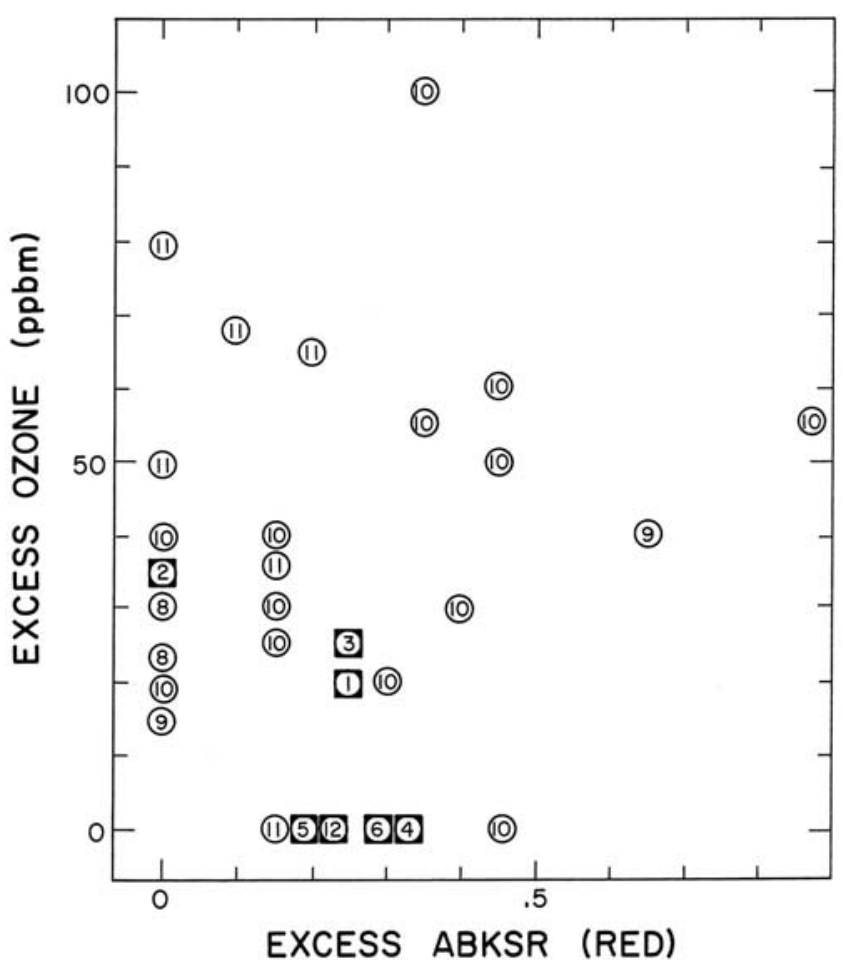

Figure 10. Summary describing aerosol-ozone layer characteristics for 30 selected layers occurring throughout the year. Selected layers containing both aerosol and ozone have well correlated profile structure. The numbers indicate the month, and for easier visualization the nonburning season months are in square boxes.

they have also been included with the ITCZ group. From this limited data, it would appear that there is a tendency for the lower layers $(4-10 \mathrm{~km})$ to have originated in or on the way from Africa and the Atlantic, while the higher-altitude layers $(11-17 \mathrm{~km})$ may have originated in Brazil, South America or perhaps farther west in the Pacific. The layers from Africa/ Atlantic also show a tendency to be in descending, dry air which would be consistent with deep convective sources far to the east of Natal. Our association of layer altitude and source regions would appear consistent with those reported by others for Natal air mass trajectories but the previous results are for a more limited time period and altitude range [Thompson et al., 1996a, 2003].

[29] Further improvements are being made to refine the geographical source region and probable origin of the layers by linking the back trajectories with concurrent satellite pictures of convective activity and outflow moving in the same direction as the trajectory. However, this is proving to be a rather ambitious and detailed project with slowly emerging results.

\subsection{Layer Formation and Evolution}

[30] As suggested above, an explanation of the layer characteristics as observed over Natal may depend on a detailed understanding of a number of processes such as convective injection (including entrainment of ambient air) into the FT with subsequent outflow and evaporation, wet removal of aerosols and soluble trace gases, photochemical evolution of both ozone and aerosols, and the nature of long 


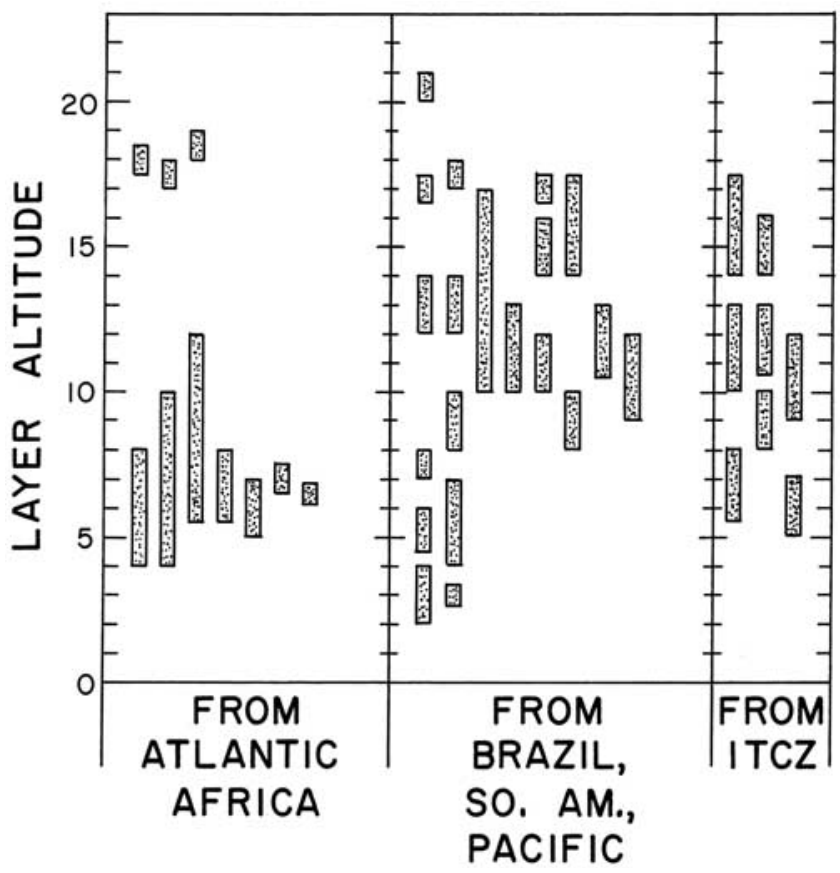

Figure 11. Summary of possible air mass back trajectories origins for the selected layers.

distance filamentary transport which incorporates possible influences of mixing dilution. Even a minimal treatment of these issues along with adequately described formation scenarios is beyond the scope of this report. However, a few preliminary constraints and conclusions seem evident.

[31] It would appear from our results that if the FT layers originated from convective injection of PBL air, significant removal and/or dilution of the aerosols responsible for the observed FT backscatter must have always occurred. Except in clouds, the FT layer ABKSR enhancements are quite modest, being only $1-10 \%$ of the PBL aerosols, suggesting that no nonmodifying direct injection has occurred. Furthermore, it is not likely that the nonprecipitating clouds observed in the FT still contain a significant amount of the aerosol responsible for the PBL backscatter, since upon dissipation through evaporation relatively large ABKSR values would have remained and been detected in at least some of the soundings, because it is relatively certain that the backscattersondes passed through at least a few of these dissipated/evaporated clouds.

[32] Since ozone is not significantly water soluble, one might expect that the high ozone values associated with the PBL in burning regions ( $80-100$ ppbv) could be convectively injected directly into the FT and be observed by the backscattersonde in layers associated with outflow clouds or dissipated outflow clouds. However, we have not observed instances of significant in-cloud ozone enhancements over Natal. This could be explained by a large amount of entrainment/dilution in developing convection and, as a consequence, the process would not tend to directly produce recognizable enhancement associated with such layers. Alternatively, the lack of any fresh cloud-ozone correlation might be explained if the clouds we observed over Natal were associated with convective injection of air containing ordinary levels of ozone not significantly different from the air surrounding the cloud. However, since Natal is near extensive burning regions, it would seem highly probably that at least some clouds from convective activity associated with elevated PBL ozone were sampled with the backscattersonde and that we should have at least a few outstanding examples of cloud-ozone correlated layers if such a relationship, in fact, exists.

[33] The above preliminary considerations suggest that the enhanced levels of ozone in the FT layers (assuming that they are not of stratospheric origin) result primarily or entirely from in situ photochemical production, since the ozone concentration in the initial layer is apparently not detectably enhanced above the surrounding air. However, a scenario for no initial ozone enhancement would require the convective outflow layer to still contain sufficient ozone precursor gases, which would be possible if they were not removed in the convection process and had sufficiently high concentration in the PBL to survive dilution processes. The possibility and probability of significant FT ozone production associated with injected layers from biomass burning sources seems well founded [Pickering et al., 1996] and the occurrence of precursor gas layers without ozone enhancement in a probable ITCZ convective outflow layer has also been reported [Mühle et al., 2002]. In addition, some authors have simply presumed that the excess ozone in the FT over Brazil was from deep convective injection of pollution products that react to produce ozone [Thompson et al., 1996b].

[34] The possibility of photochemical aerosol production occurring along with ozone production in the FT layers is an obvious question but has not been treated in detail. It is not even clear that such gas to particle production would be required to explain the aerosol layers we have observed during the burning season since the very high concentration of aerosols in the PBL may survive removal and dilution in convective injection processes to the extent required for our detection and identification. However, without settling the question of secondary aerosol production in the evolving layers, one might argue that not even a rudimentary appreciation of the fundamental FT chemistry has been achieved.

\subsection{Transtropopause Layers}

[35] As noted above, transient layers just above the local tropopause can be seen in Figures 5 and 6 . Evidence of these layers have appeared in multiple years in successive soundings starting near the middle to end of the burning season and contain stratospheric ozone levels and particle sizes similar to the surrounding air of the stratosphere. The isolated occurrence of such a layer would usually signal the occurrence of a small volcanic eruption just large enough to marginally penetrate the tropopause. In this case, however, the time, regularity and height of occurrence might instead suggest a biomass burning origin with injection at the top of the very highest occurring cumulative developments and associated cirrus outflow. On six occasions we have observed cirrus clouds with weak diffuse tops extending into the stratosphere and taking on the higher ozone values of the surrounding stratospheric air as well as exhibiting particle sizes more typical of stratospheric air than of cloud particles. The ubiquitous wind gradients could eventually separate the stratospheric portion of these diffuse top cirrus from the main cloud, resulting in isolated above-tropopause or transtropopause layers. Subsequently, such detached layers could be transported to regions where the local 
tropopause is at a significantly lower altitude. Thus these layers at Natal could be a measure of the very highest cumulative injections taking place in the tropics. However, our limited number of soundings does not preclude the possibility that at least some of the transtropopause layers are not, in fact, of volcanic origin. For example, it is tempting to associate the layers near $20 \mathrm{~km}$ in Figure 6 with the eruption of Reventador $\left(0.078^{\circ} \mathrm{S}, 77.656^{\circ} \mathrm{W}\right)$ on 4 November 2002 [Wunderman et al., 2002], which reportedly sent an ash cloud to $15-17 \mathrm{~km}$. However, back trajectory analysis and launch date does not support this origin, but the proximity in time and space is suspiciously close. Furthermore, the layer CI is not consistent with fresh ash particles but is more representative of background stratospheric aerosol. At the time of this writing (July 2003), the layer continues to be detectable and apparently risen to $22 \mathrm{~km}$. Hopefully, this question can be resolved with the continuing sounding program.

\subsection{Column Loadings}

[36] The integrated column backscatter has been calculated for the PBL, FT and stratosphere employing the altitude boundaries as determined by the appropriate sounding. Using the FT average aerosol conditions of Figure 3 as a baseline for undisturbed profiles, it is found that about $85 \%$ of the total atmospheric column aerosol backscatter in the red channel can be attributed to the PBL, about $13 \%$ to the FT and $2-3 \%$ to the stratosphere. The average above baseline contribution of the FT enhancements shown in Figure 1, presumably from biomass burning activity, increases the column backscatter for this region by a factor of $\sim 1.35$. Although this is not a large factor, it still may be important because it is probably applicable on a global scale at tropical latitudes in contrast to the comparatively small biomass burning regions influencing the PBL on local scales.

\subsection{Comparison to Other Latitudes}

[37] As indicated above, we interpret the profiles of Figure 3 to represent undisturbed conditions that might be effectively used to define a baseline or background for the FT with typical values of ABKSR $\approx 0.15$. Figure 4 also shows minimal disturbances except for the lower FT, where there is the influence of the CFT type profile as discussed above. In comparing Figures 3 and 4 with profiles containing disturbances (Figures 1, 5, and 6) it would appear that the same general underlying baseline profile $(\mathrm{ABKSR} \approx$ 0.15 ) is still evident in the disturbed soundings but with superimposed layers or perturbations. These same features are also suggested in the backscattersonde data taken at northern midlatitudes [Rosen et al., 1997, 2000] southern midlatitudes [Liley et al., 2001] and arctic regions [Suortti et al., 2001] but involving different perturbation sources. If substantiated, this view of FT aerosol similarity would present a simplifying or organizational aspect to the interpretation of global FT aerosols. Additionally, it would indicate that the indiscriminate averaging of profiles could destroy information and lead to unrealistic profile shapes that never actually occur in nature.

\section{Conclusion}

[38] A clear annual aerosol enhancement can be observed in the FT over Natal during the burning season. Many of these layers occur congruently with ozone enrichments, which are also thought to be at least partially associated with the burning season. Trajectory analysis suggests that some of the layers, typically those at lower altitudes, have originated over the Atlantic or Africa while the higheraltitude layers tend to originate over Brazil or possibly the Pacific. A peculiar step decay in the aerosols at $20 \mathrm{~km}$ during the final stages of the Pinatubo volcanic influence was observed but the data is not of sufficient regularity to convincingly test possible explanations. The general nature of the ABKSR profile over Natal can be described in terms identical to those used for other latitudes: the FT ABKSR seems to exhibit a quasi-constant background or baseline profile which is perturbed by seasonally dependent layers of higher ABKSR. The simultaneous cloud/ozone measurements provided by the backscattersonde indicate PBL air (typically containing ozone concentrations of $80 \mathrm{ppbv}$ or more during the burning season) that experiences cloud formation with convective injection into the FT, initially does not contain ozone levels noticeably different from the surrounding FT air. Aerosol layers just above the local tropopause have been observed in what may prove to be an annual cycle but continuing observations are needed to confirm their proposed explanations. We hope that the preliminary results reported here will serve to bring further attention to the wealth of FT information potentially available through systematic measurements of multiple parameters using current cost effective technology.

[39] Acknowledgments. This work was supported by NSF under grant ATM-0086484 and the Brazilian Instituto Nacional de Pesquisas Espaciais (INPE). We gratefully acknowledge the enthusiastic and competent balloon launch support provide by Carlos R. da Silva, Edmilson L. da Silva, and Tercio L. B. Penha.

\section{References}

Carlson, D., and J. Wang (2002), RS80 humidity data set corrections, Vaisala News, 159, 14-15.

Draxler, R. R. (1996), Boundary layer isentropic and kinematic trajectories during the August 1993 North Atlantic Regional Experiment Intensive, J. Geophys. Res., 101, 22,255-29,268.

Huesmann, A. S., and M. H. Hitchman (2001), The stratospheric quasibiennial oscillation in the NCEP reanalyses: Climatological structures, J. Geophys. Res., 106, 11,859-11,874.

Kaufman, Y. J., et al. (1998), Smoke Clouds and Radiation-Brazil (SCAR-B) Experiment, J. Geophys. Res., 103, 31,783-31,808.

Kirchhoff, V. W. J. H., R. A. Barnesw, and A. L. Torres (1991), Ozone climatology at Natal from in situ ozonesonde data, J. Geophys. Res., 96, 10,899-10,909.

Liley, J. B., J. M. Rosen, N. T. Kjome, N. B. Jones, and C. P. Rinsland (2001), Springtime enhancement of upper tropospheric aerosol at $45 \mathrm{deg}$ S, Geophys. Res. Lett., 28, 1495-1498.

Mühle, J., et al. (2002), Biomass burning and fossil fuel signatures in the upper troposphere observed during a CARIBIC flight from Namibia to Germany, Geophys. Res. Lett., 29(19), 1910, doi:10.1029/ 2002 GL015764.

Niwano, M., and M. Shiotani (2001), Quasi-biennial oscillation in vertical velocity inferred from trace gas data in the equatorial lower stratosphere, J. Geophys. Res., 106, 7281-7290.

Oltmans, S. J., et al. (2001), Ozone in the Pacific tropical troposphere from ozonesonde observations, J. Geophys. Res., 106, 32,503-32,525.

Ovarlez, J., et al. (2002), Water vapour measurements inside cirrus clouds in Northern and Southern Hemispheres during INCA, Geophys. Res. Lett., 29(16), 1813, doi:10.1029/2001GL014440.

Pickering, K. E., et al. (1996), Convective transport of biomass burning emissions over Brazil during TRACE A, J. Geophys. Res., 101, 22,99323,012.

Prins, E. M., J. M. Feltz, W. P. Menzel, and D. E. Ward (1998), An overview of Goes- 8 diurnal fire and smoke results for SCAR-B and 1995 fire season in South America, J. Geophys. Res., 103, 31,82131,835 . 
Rosen, J. M., and V. W. J. H. Kirchhoff (1997), Balloonborne aerosol and ozone measurements over central Brazil during a period of intense biomass burning, in SCAR-B Proceedings, edited by V. W. J. H. Kirchhoff, pp. 183-186, Transtec Ed., São José dos Campos, Brazil.

Rosen, J. M., and N. T. Kjome (1991), The backscattersonde: A new instrument for atmospheric aerosol research, Appl. Opt., 30, 1552-1561.

Rosen, J. M., N. T. Kjome, and S. J. Oltmans (1993), Simultaneous ozone and polar stratospheric cloud observations at South Pole Station during winter and spring 1991, J. Geophys. Res., 98, 12,741-12,751.

Rosen, J. M., N. T. Kjome, and J. B. Liley (1997), Tropospheric aerosol backscatter at a midlatitude site in the northern and southern hemispheres, J. Geophys. Res., 102, 21,329-21,339.

Rosen, J. M., S. Young, J. Laby, N. T. Kjome, and J. Gras (2000), Springtime aerosol layers in the free troposphere over Australia: Mildura Aerosol Tropospheric Experiment (MATE 98), J. Geophys. Res., 105, $17,833-17,842$.

Suortti, T., et al. (2001), Evolution of the Arctic stratospheric aerosol mixing ratio measured with balloon-borne aerosol sondes for the years 1998-2000, J. Geophys. Res., 106, 20,759-20,766.

Thompson, A. M., M. K. E. Pickering, D. P. McNamara, M. R. Schoeberi, R. D. Hudson, J. H. Kim, E. V. Browell, V. W. J. H. Kirchhoff, and D. Nganga (1996a), Where did tropospheric ozone over southern Africa and the tropical Atlantic come from in October 1992? Insights from TOMS, GTE, TRACE A and SAFARI 1992, J. Geophys. Res., 101, $24,251-24,278$

Thompson, A. M., D. P. McNamara, V. W. J. H. Kirchhoff, and A. Setzer, (1996b), Tropospheric ozone at Cuiabá during SCAR-B and TRACE-A, in SCAR-B Proceedings, pp. 191-194, Transtec Ed., São José dos Campos, Brazil.

Thompson, A. M., et al. (2003), Southern Hemisphere Additional Ozonesondes (SHADOZ) 1998-2000 tropical ozone climatology: 2. Tropospheric variability and the zonal wave-one, J. Geophys. Res., 108(D2), 8241, doi:10.1029/2002JD002241.

Wunderman, R., J. Fela, E. Venzke, and G. Mayberry (Eds.) (2002), Reventador, Bull. Global Volcan. Network, 27(11), 2-5.

F. R. da Silva, Laboratorio Ozonio, Instituto Nacional de Pequisas Espaciais (INPE), 59001-970 Natal, Brazil.

V. W. J. H. Kirchhoff, Laboratorio Ozonio, Instituto Nacional de Pequisas Espaciais (INPE), 12227-010 São José dos Campos, Brazil.

N. T. Kjome, R. M. Morales, and J. M. Rosen, Department of Physics and Astronomy, University of Wyoming, Laramie, WY 82071, USA. (raym@uwyo.edu) 